\title{
Studi pengaruh perbedaan warna umpan buatan pancing gurita terhadap hasil tangkapan
}

\author{
Studi of artiticial bait with different color of octopus fishing rod to catches
}

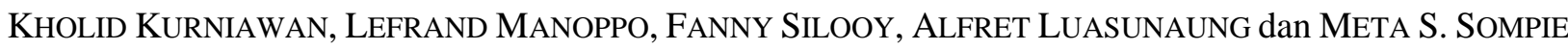 \\ Program Studi Pemanfaatan Sumberdaya Perikanan, Fakultas Perikanan dan Ilmu Kelautan Universitas \\ Sam Ratulangi Manado, 95115
}

\begin{abstract}
The western part of North Minahasa waters is mainly covers by coral reef with relatively large potential of fishery resources including Octopus. Fishermen of Budo village catches the Octopus by fishing gear known as sihoru or gara - gara boboca in local name with classified as trowling. The goals of this study are to analyze the influence of using different colors of typical bait released to fishing catch and to identity the catches species. Experimental method and T-Test wore using to analyze the data. The result indicated that the color differences not influence to the number of catches, which the analysis probability of brown and black colors is 0.6041 , the brown and red is 0.4762 , the black and red is 0.8455 which all of these numbers or higher than $\alpha 0.05=2.2281$. Based on this identification, Octopus cyanea is mainly catches.
\end{abstract}

Keywords: sihoru line, color of artificial bait, Octopus cyanea

\begin{abstract}
ABSTRAK
Perairan Minahasa Utara bagian Barat pada umumnya merupakan hamparan batu karang yang memiliki potensi sumber daya perikanan yang relatif melimpah salah satunya adalah gurita (Octopus). Dalam memanfaatkan sumber daya ini masyarakat nelayan Desa Budo menangkap gurita menggunakan alat tangkap pancing yang disebut sihoru atau gara-gara boboca, alat tangkap ini adalah alat tangkap pancing jenis tonda. Tujuan dalam penelitian ini adalah menganalisis pengaruh penggunaan warna umpan terhadap jumlah hasil Tangkapan dan mengetahui spesies octopus hasil tangkapan. Metode yang digunakan dalam penelitan adalah eksperimental dan dianalisis menggunakan metode statistik Uji T. Dari penelitian ini diperoleh hasil nilai analisis P coklat hitam dan sebesar 0.6041, coklat dan merah sebesar 0.4762 , hitam dan merah sebesar 0.8455 yang semua nilainya berada diatas $\alpha 0.05=2.2281$ dan dapat disimpulkan bahwa perlakuan warna umpan tidak berpengaruh terhadap hasil tangkapan. Berdasarkan hasil identifikasi gurita yang tertangkap adalah Octopus cyanea.
\end{abstract}

Kata-kata kunci: pancing sihoru, warna umpan buatan, Octopus cyanea

\section{PENDAHULUAN}

Perairan Minahasa Utara bagian barat pada umumnya merupakan hamparan batu karang yang memiliki potensi sumberdaya perikanan yang relatif melimpah salah satunya adalah gurita (Octopus). Hewan ini menghuni dasar perairan yang berkarang maupun berpasir (Bagus, 2018).

Nelayan di Kecamatan Wori menangkap gurita menggunakan pancing, jubi (harpoon), serta menggunakan tangan secara langsung. Desa Budo merupakan desa yang berada di kecamatan tersebut dalam menangkap octopus menggunakan alat tangkap pancing yang dalam bahasa lokal disebut sihoru atau gara-gara boboca. Alat tangkap pancing ini menggunakan umpan buatan yang terdiri dari bagian kepala atau badan terbuat dari batu ataupun cor beton, kemudian dilekatkan kain kursi sofa dan payung bekas yang dirangkai sedemikian rupa menyerupai bentuk gurita.

Prinsip penangkapan dari pancing sihoru hampir sama dengan pancing tonda. Pancing tonda merupakan alat tangkap ikan tradisional yang

*Penulis untuk penyuratan; email: kholidkurniawan30@gmail.com 
memakai umpan tiruan untuk mengelabui penglihatan ikan dan umumnya untuk menangkap jenis-jenis ikan pelagis. Suatu benda dalam air dapat terlihat tergantung dari kemampuan retina mata untuk menyerap warna yang dipantulkan oleh benda tersebut (Imbir et al 2015). Pancing tonda ditujukan untuk menangkap ikan pelagis sedangkan pancing sihoru digunakan untuk menangkap gurita. Tingkah laku Octopus yang bersifat pemangsa serta kanibal, maka digunakan umpan buatan yang menyerupai gurita serta memiliki warna yang berbeda-beda agar menarik perhatian dari target penangkapan.

Berdasarkan pemikiran di atas, maka diadakan penelitian tentang pengaruh penggunaan warna umpan terhadap jumlah tangkapan pancing sebagai bahan pertimbangan dalam pengembangan perikanan gurita di Sulawesi Utara.

\section{METODE PENELITIAN}

Kegiatan penelitian dilaksanakan pada perairan sekitar Desa Budo Kecamatan Wori, Kabupaten Minahasa Utara, Provinsi Sulawesi Utara dengan posisi geografis daerah penangkapan, yaitu 10 36'04" N, 124051'28" E yang berada di perairan Wori sampai pada 1038'04" N, 124o53'59" E yang berada perairan Darunu. Penelitian ini dilaksanakan pada bulan Maret sampai dengan Mei 2019. Metodologi yang digunakan adalah metode eksperimental yaitu suatu rancangan percobaan yang diuji coba untuk memperoleh informasi tentang persoalan yang diteliti. Persoalan yang diteliti dalam penelitian adalah mengetahui pengaruh warna umpan terhadap hasil tangkapan gurita serta mengetahui spesies gurita yang tertangkap. Teknik pengambilan data yang dilakukan dengan cara perahu dijalankan menuju daerah penangkapan, perjalanan ke daerah penangkapan berkisar antara 25 hingga 30 menit dan tiba di daerah penangkapan pada pukul 05.00 wita. Setelah tiba di fishing ground, maka perahu penangkap diatur secara acak dengan membentuk formasi yang sejajar kemudian dijalan perlahanlahan secara bersamaan. Operasi penangkapan dilakukan pada pukul 05.00 wita. Jika salah satu pancing memperoleh hasil tangkapan maka perahu lainnya harus berhenti setelah itu perahu dijalankan kembali sesuai dengan arah yang ditentukan. Hal tersebut dilakukan hingga pada pukul 09.30 wita. Setelah selasai perahu dijalankan menuju fishing base. Setelah tiba maka hasil tangkapan dari setiap perlakuan diturunkan dari atas perahu dan dilakukan pencataan dan pengukuran panjang total serta penimbangan berdasarkan warna umpan buatan, kemudian untuk mengetahui jenis gurita dilakukan identifikasi dengan menggunakan buku identifikasi Roper et al (1984).

Perahu yang digunakan dalam penelitian berukuran panjang $4 \mathrm{~m}, 5 \mathrm{~m}$ dan $7 \mathrm{~m}$ (Gambar 1). Sedangkan sebagai tenaga pengerak menggunakan mesin katinting $6 \mathrm{Pk}$ untuk perahu yang berukuran $7 \mathrm{~m}$, kemudian untuk panjang 4 dan 5 menggunakan mesin katinting $5.5 \mathrm{Pk}$.

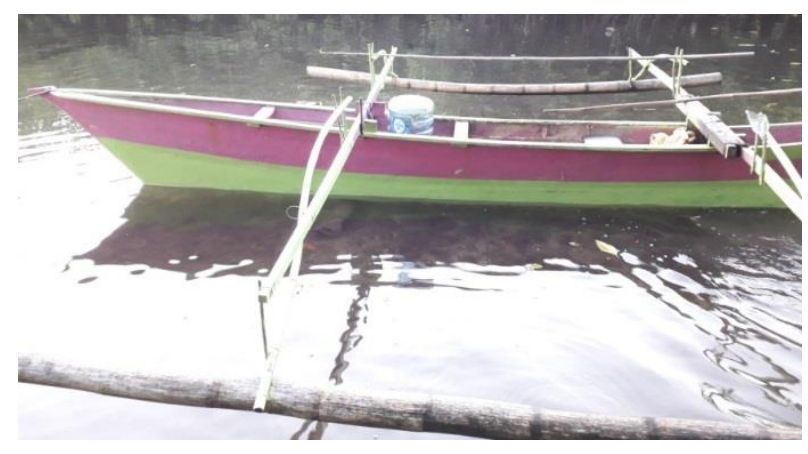

Gambar 1. Perahu tipe pelang yang digunakan dalam penelitian

Alat tangkap yang digunakan dalam penelitian ini adalah tiga unit pancing, Tiap unit pancing terdiri dari penggulung tali (spoon), tali pancing (main line) dan umpan buatan, sedangkan spesifikasi pancing disajikan pada Tabel 1 dan konstruksi pada Gambar 2. Material umpan buatan yang digunakan berbahan kain sofa beludru bekas dengan ukuran $0.25 \mathrm{~m} 2$, kain payung bekas, tali pancing No. 1000 bahan PA monofilament, penggulung pancing berbahan kayu, sedangkan pemberat yang digunakan adalah batu atau cor beton yang dibuat sedemikian rupa menyerupai kepala atau badan Octopus, kemudian dibungkus dengan kain beludru dan kain payung kemudian diikat. Setelah selesai kain sofa dan payung digunting menyerupai legan atau tentakel Octopus. Alat bantu yang digunakan dalam menunjang operasi penangkapan adalah alat pengait (ganco) untuk mengambil hasil.

Operasi penangkapan dilakukan dengan cara menurunkan pancing hingga pada kedalaman 1-12 meter. Setelah itu perahu dijalankan secara perlahan-lahan dengan menggunakan dayung agar posisi umpan buatan berada di atas dasar perairan. Ketika terlihat ada gurita yang mengejar atau mengikuti umpan tersebut, maka secara perlahanlahan tali pancing ditarik mendekati perahu dan 
pada saat yang bersamaan segera mempersiapkan ganco, untuk mengait hasil tangkapan.

Analisis yang digunakan untuk mengetahui pengaruh dari ketiga perlakuan warna umpan adalah uji $\mathrm{T}$, secara statistik untuk menguji kebenaran atau kepalsuan hipotesis nol (Riduwan, 2006). Dari sampel yang akan diambil, maka digunakan analisis fungsion TTEST pada program microsoft exel 2007 dengan sistematis total hasil tangkapan disajikan pada tabel 2.

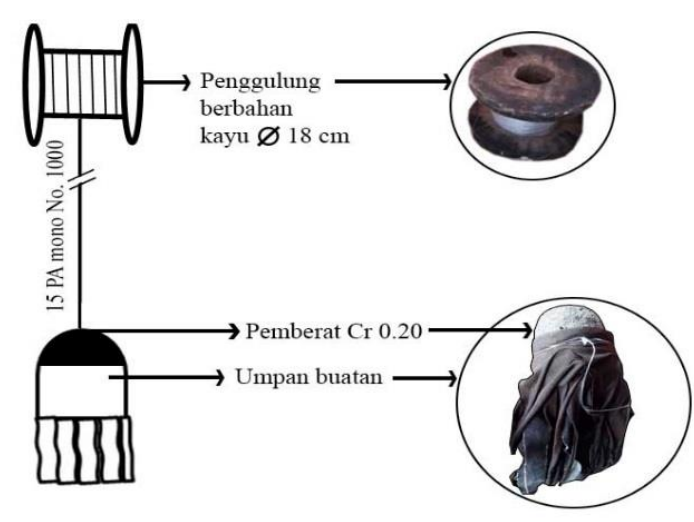

Gambar 2. Konstruksi pancing gurita

Table 1. Spesifikasi alat tangkap

Alat tangkap utama

Penggulung pancing

\begin{tabular}{|c|c|c|c|c|c|}
\hline No & Material & Diameter $(\mathrm{cm})$ & Jumlah & & \\
\hline 1 & Kayu Wd & 18 & 3 & & \\
\hline \multicolumn{6}{|c|}{ Tali pancing } \\
\hline No & Material & Diameter benang & Panjang (m) & & Jumlah \\
\hline 1 & PA mono & No 1000 & 15 & & 3 \\
\hline \multicolumn{6}{|c|}{ Pemberat } \\
\hline No & Material & Diameter $(\mathrm{m})$ & Masa $(\mathrm{kg})$ & Warna & Jumlah \\
\hline 1 & Batu cor $\mathrm{Cr}$ & 0.20 & 0.5 & - & 3 \\
\hline \multicolumn{6}{|c|}{ Umpan buatan } \\
\hline No & Material & Diameter $(\mathrm{m})$ & Masa $(\mathrm{kg})$ & Warna & Jumlah \\
\hline 1 & $\begin{array}{l}\text { Kain beludru } \\
\text { (bagian luar) }\end{array}$ & $0.5 \times 0.5$ & - & $\begin{array}{l}\text { Coklat, hitam } \\
\text { dan Merah }\end{array}$ & 3 \\
\hline 2 & $\begin{array}{l}\text { Kain nylon } \\
\text { (bagian } \\
\text { dalam) }\end{array}$ & $0.5 \times 0.5$ & - & $\begin{array}{l}\text { Coklat muda, } \\
\text { merah, dan } \\
\text { abu-abu }\end{array}$ & 3 \\
\hline \multicolumn{6}{|c|}{ Alat bantu pengait (ganco) } \\
\hline No & Material D & ameter $(\mathrm{m})$ & Panjang $(\mathrm{m})$ & Jumlah & \\
\hline 1 & Kayu & & 4 & 3 & \\
\hline 2 & Besi Fe & & 0.06 & 3 & \\
\hline
\end{tabular}

Table 2. Sistematis total hasil tangkapan.

\begin{tabular}{lllll}
\hline \multirow{2}{*}{ Hari/trip } & \multicolumn{3}{c}{ Warna umpam } & Total \\
\cline { 2 - 4 } & Coklat & Hitam & Merah & \\
\hline 1 & C1 & H1 & M1 & t1 \\
2 & C2 & H2 & M2 & t2 \\
3 & C3 & H3 & M3 & t3 \\
4 & C4 & H4 & M4 & t4 \\
5 & C5 & H5 & M5 & t5 \\
6 & C6 & H6 & M6 & t6 \\
\hline Total & T1 & T2 & T3 & $\Sigma$ \\
Rata-rata & R1 & R2 & R3 & \\
\hline
\end{tabular}

Secara umum rumus yang digunakan dalam uji $\mathrm{T}$ (Syofian, 2017) adalah sebagai berikut:

$\bar{x}_{i}=\frac{\sum X_{i}}{n}$

$$
\begin{aligned}
& S_{i}^{2}=\sum \frac{\left(X_{i}-\bar{X}_{i}\right)^{2}}{n_{1}-1} \\
& \mathrm{~T}_{\text {hitung }}=\frac{\bar{X}_{1}-\bar{X}_{2}}{\sqrt{\frac{\left(n_{1}-1\right) S_{1}^{1}+\left(n_{2}-1\right) S_{2}^{1}}{n_{1}+n_{2}}\left(\frac{1}{n_{1}}+\frac{1}{n_{2}}\right)}}
\end{aligned}
$$

Keterangan:

$\mathrm{X}=$ Data pengukuran perlakuan

$\bar{X}=$ Rata-rata pengukuran perlakuan

$\mathrm{S} 2$ = Standart deviasi

$\mathrm{n}=$ Jumlah pengamatan

Dari hasil analisis data maka variabel-variable yang akan diuji dalam penelitian ini dilanjutkan dengan penentuan hipotesis, yaitu menolak Ho atau merima Ho berdasarkan penentuan hipotesis 
pada hasil analisis uji $\mathrm{T}$ dan di bandingkan dengan Ttabel (Syofian, 2017), dimana:

a. Ho diterima (H1, ditolak) apabila $\mathrm{T}_{\text {hitung }} \leq \mathrm{T}_{\text {tabel }}$ tidak berpengaruh terhadap hasil tangkapan

b. Ho ditolak (H1, diterima) apabila $T_{\text {hitung }} \geq T_{\text {tabel }}$ berpengaruh terhadap hasil tangkapan

\section{HASIL DAN PEMBAHASAN}

\section{Total hasil tangkapan}

Hasil tangkapan yang diperoleh selama penelitian yang dilakukan menggunakan pancing gurita dengan perlakuan 3 (tiga) warna umpan dan berlasung selama 6 trip diperoleh hasil tangkapan sebanyak 32 ekor dengan rincian untuk umpan yang berwarna cokelat sebanyak 13 ekor (41\%), umpan berwarna hitam sebanyak 10 ekor (31\%) dan umpan yang berwarna merah diperoleh sebanyak 9 ekor (28\%). Komposisi hasil tangkapan disajikan pada Tabel 3 dan Gambar 3.

Table 3. Total hasil tangkapan (ekor)

\begin{tabular}{lllll}
\hline Hari/trip & \multicolumn{2}{l}{ Warna umpan } & $\begin{array}{l}\text { Total } \\
\text { (ekor) }\end{array}$ \\
\cline { 2 - 4 } & Cokelat & Hitam & Merah & 7 \\
\hline 1 & 3 & 1 & 3 & 7 \\
2 & 5 & 4 & 2 & 11 \\
3 & 2 & 1 & 1 & 4 \\
4 & 1 & 0 & 0 & 1 \\
5 & 2 & 1 & 0 & 3 \\
6 & 0 & 3 & 3 & 6 \\
\hline Total (ekor) & 13 & 10 & 9 & 32 \\
Persentasi (\%) & 41 & 31 & 28 & 100 \\
\hline
\end{tabular}

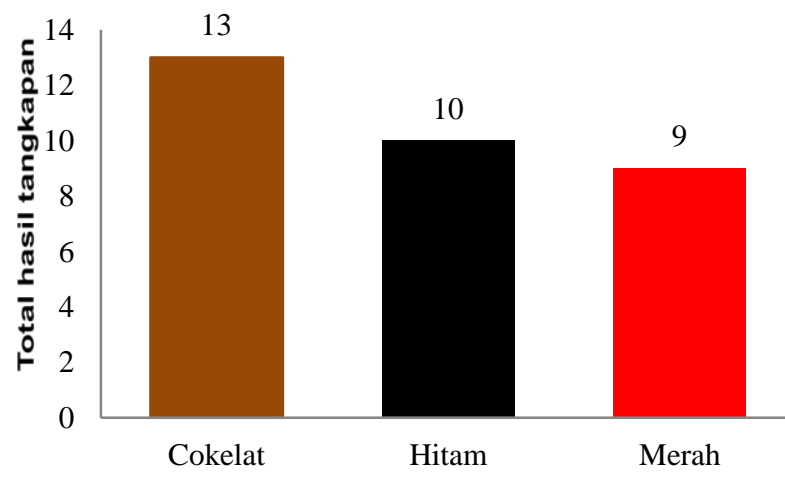

Gambar 3. Grafik total hasil tangkapan dari setiap warna umpan.

\section{Hasil analisis Data}

Sesuai dengan tujuan penelitian, yaitu mengetahui pengaruh warna umpan buatan terhadap hasil tangkapan maka dilakukan analisis dengan menggunakan uji $\mathrm{T}$ yang dikerjakan berdasarkan analisis statistik deskriptif dalam Tabel 4.

Tabel 4. Analisis statistik deskriptif

\begin{tabular}{llll}
\hline & Cokelat & Hitam & Merah \\
\hline Mean & 2.166667 & 1.666667 & 1.5 \\
Standard Error & 0.703167 & 0.614636 & 0.562731 \\
Median & 2 & 1 & 1.5 \\
Mode & 2 & 1 & 3 \\
Standard Deviation & 1.722401 & 1.505545 & 1.378405 \\
Sample Variance & 2.966667 & 2.266667 & 1.9 \\
Kurtosis & 0.814291 & -0.64879 & -2.29917 \\
Skewness & 0.678436 & 0.840032 & 0 \\
Range & 5 & 4 & 3 \\
Minimum & 0 & 0 & 0 \\
Maximum & 5 & 4 & 3 \\
Sum & 13 & 10 & 9 \\
Count & 6 & 6 & 6 \\
\hline
\end{tabular}

Dari analisis statistik deskriptif di atas, uji $\mathrm{T}$ dianalisis berdasarkan ragam contoh (Sample Variance) yang menunjukkan hasil dua variable cokelat dan hitam, cokelat dan merah, hitam dan merah memperoleh hasil nilai berbeda (Tabel 4).

Berdasarkan analisis uji $\mathrm{T}$ (Tabel 4) nilai $\mathrm{P}$ cokelat dan hitam 0.6041, cokelat dan merah 0.4762 dan hitam dan merah 0.8455 yang semua nilainya berada diatas $\alpha 0.05=2.2281$. Secara statistik nilai tersebut memberikan hasil bahwa Ho diterima yang memberikan arti bahwa tidak ada perbedaan yang nyata dari seluruh perlakuan warna umpan.

\section{Ukuran Panjang Total dan Berat Hasil Tangkapan}

Kisaran ukuran panjang total hasil tangkapan yang diperoleh selama penelitian berkisar antara 0.7-1.2 meter (Tabel 5), dengan rincian ukuran panjang total $0.9-10 \mathrm{~m}$ berjumlah 16 ekor, ukuran panjang total $0.7-0.8 \mathrm{~m}$ dan $1.1-1.2 \mathrm{~m}$ masing-masing berjumlah 7 ekor. 
Tabel 4. Analisis Uji T

\begin{tabular}{lllllll}
\hline & \multicolumn{2}{l}{ Cokelat dan Hitam } & \multicolumn{2}{l}{ Coklat dan Merah } & \multicolumn{2}{l}{ Hitam dan Merah } \\
\hline Mean & 2.1667 & 1.6667 & 2.1667 & 1.5 & 1.6667 & 1.5 \\
Variance & 2.9667 & 2.2667 & 2.9667 & 1.9 & 2.2667 & 1.9 \\
Observations & 6 & 6 & 6 & 6 & 6 & 6 \\
Df & 10 & & 10 & & 10 & \\
t Stat & 0.5354 & & 0.7402 & & 0.2 & \\
P(T<=t) two-tail & 0.6041 & & 0.4762 & & 0.8455 & \\
t Critical two-tail & 2.2281 & & 2.2281 & & 2.2281 & \\
\hline
\end{tabular}

Table 5. Panjang total hasil tangkapan

\begin{tabular}{cc}
\hline Panjang total (m) & Jumlah ekor) \\
\hline $0.7-0.8$ & 7 \\
$0.9-1.0$ & 16 \\
$1.1-1.2$ & 7 \\
\hline
\end{tabular}

Kisaran berat per individu berkisar antara 1-2.6 $\mathrm{kg}$ (Tabel 6). Rincian ukuran berat hasil tangkapan $1.0-1.3 \mathrm{~kg}$ sebanyak 17 ekor, berat $1.4-1.7 \mathrm{~kg}$ sebanyak 6 ekor, berat $1.8-2.0 \mathrm{~kg}$ sebanyak 2 ekor dan berat di atas $2.0 \mathrm{~kg}$ sebanyak 5 ekor. Komposisi panjang total dan berat hasil tangkapan selama penelitian disajikan pada Tabel 6 .

Table 6. Berat hasil tangkapan

\begin{tabular}{cc}
\hline Berat $(\mathrm{kg})$ & Jumlah (ekor) \\
\hline $1.0-1.3$ & 17 \\
$1.4-1.7$ & 6 \\
$1.8-2.0$ & 2 \\
$>2.0$ & 5 \\
\hline
\end{tabular}

\section{Pembahasan}

Hasil analisis statistik menggunakan uji $\mathrm{T}$ yang diperoleh berdasarkan ragam contoh (Sample Variance) memperlihatkan bahwa perlakuan umpan berwarna tidak berpengaruh terhadap hasil tangkapan.

Namun, penggunaan warna umpan pada pancing sihoru memperlihatkan bahwa warna umpan yang paling dominan menarik perhatian gurita adalah umpan berwarna cokelat sebanyak 13 ekor (41\%), kemudian diikuti oleh warna hitam sebanyak 10 ekor (31\%) dan warna merah sebanyak 9 ekor
(29\%). Perbedaan total hasil tangkapan dari ketiga warna umpan kerena pada saat umpan yang berwarna berada dalam perairan akan mengalami penyerapan. Sebab warna merah memiliki spectrum cahaya lebih panjang sehingga akan lebih cepat menghilang pada kedalaman tertentu sedangkan untuk warna cokelat dan hitam memiliki spektrum cahaya pendek dan dengan demikian penyerapan di dalam air lebih kurang sehingga akan lebih jelas terlihat oleh ikan target. Warna hitam memperoleh hasil yang lebih sedikit dibandingkan warna coklat karena gurita menganggap bahwa umpan berwarna hitam bukan makanannya, sedangkan cokelat akan terlihat samar-samar sebagai makanannya sehingga gurita tersebut lebih tertarik kepada warna umpan cokelat.

Menurut Wood and O'Do (1997) bahwa mata gurita dapat membedakan polarisasi cahaya dalam perairan. Hal ini, sangat tergantung pada kondisi lingkungan perairan, dari pengamatan saat penelitian kondisi perairan menjadi salah factor penting dalam menunjang keberhasilan operasi penangkapan.

Panjang total hasil tangkapan yang diperoleh berkisar antara $0.7-1.2 \mathrm{~kg}$ hasil ini sama dengan yang dikemukakan oleh Roper et al (1984), namun untuk berat hasil tangkapan maksimum yang diperoleh hanya sebesar $2.0 \mathrm{~kg}$. Hal ini, disebabkan kondisi ekologis perairan serta penangkapan yang intensif dari nelayan yang mengejar keuntungan, sehingga terjadi pemanfaatan yang tidak melihat keberlangsungan sumberdaya gurita.

Berdasarkan hasil identifikasi terhadap hasil tangkapan gurita disimpulkan bahwa gurita ini digolongkan sebagai Octopus cyanea, karena memiliki ciri-ciri sebagai berikut: mantel berbentuk bulat lonjong, lebar serta tebal. Kepala tampak jelas dan dibatasi oleh leher, mata yang besar dan menonjol, siphon berbentuk pipa berwarna pucat lengan panjang dan mengecil pada ujungnya, paruh 
atas memiliki rostrum yang pendek, berliku serta tumpul dengan sudut pengait agak besar, paruh bawah memiliki rostrum yang pendek dan tumpul, kerudung kepala sempit serta puncak kepala melengkung puncak kepala melengkung agak panjang (Nessie, 2019; Paruntu et al, 2009).

Klasifikasi dari Octopus cyanea menurut Nessie (2019) adalah sebagai berikut:

Kingdom: Animalia

Phylum: Mollusca

Class: Cephalopoda

Ordo: Octopoda

Family: Octopodidae

Genus: Octopus

Species: Octopus cyanea

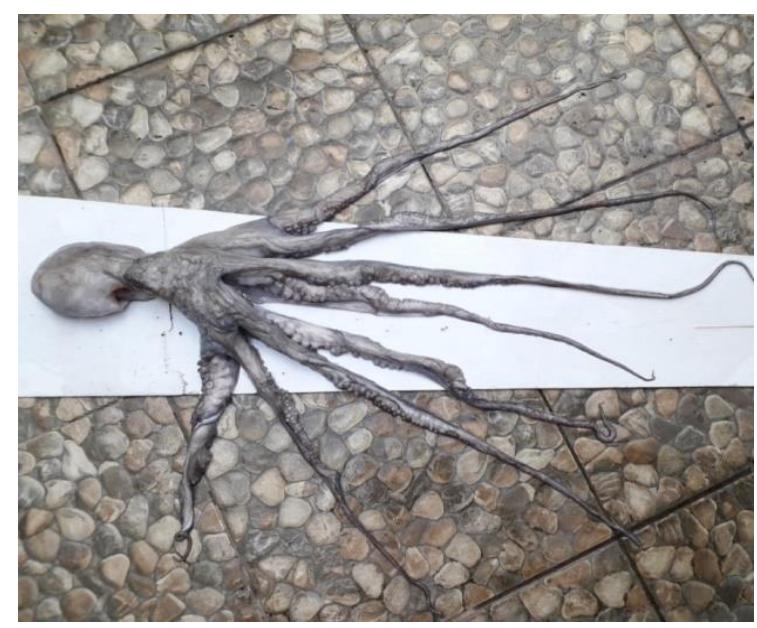

Gambar 4. Sampel hasil tangkapan Octopus Cyanea.

\section{KESIMPULAN}

Berdasarkan tujuan yang ditetapkan maka hasil analisis yang diperoleh nilai $\mathrm{P}$ coklat dan hitam sebesar 0.6041, coklat dan merah sebesar 0.4762, hitam dan merah sebesar 0.8455 yang semua nilainya berada diatas $\alpha 0.05=2.2281$ dan dapat disimpulkan bahwa perlakuan warna umpan tidak berpengaruh terhadap hasil tangkapan. Berdasarkan hasil identifikasi gurita yang tertangkap adalah Octopus cyanea.

\section{Ucapan Terima Kasih}

Terimakasih kepada bapak Anis, Nius, dan bapak Markus yang telah banyak membantu peneliti sehingga penelitian ini dapat berjalan sesuai dengan rencana.

\section{DAFTAR PUSTAKA}

Bagus Bagaskoro., 2018. Identifikasi Morfologi dan Molekuler Pada Gurita (Genus Octopus Covier, 1798) yang ditangkap di Pelabuhan Ratu, Sukabumi, Jawa Barat.

Carolus P. Paruntu, Farnis B. Boneka dan Sujito L. Talare., 2009. Gurita (cephalopoda) dariperairan Sangihe, Sulawesi Utara. EKOTON Vol. 9, No.2:13-27, Oktober 2009 ISSN 1412-3487

Fycki Fendi Imbir, Wilhelmina Patty dan Johny Wenno., 2015. Pengaruh warna umpan pada hasil tangkapan pancing tonda di perairan Teluk Manado Sulawesi Utara. Jurnal Ilmu dan Teknologi Perikanan Tangkap 2(1): 9-13, Juni 2015 ISSN 2337-4306.

Nessie VL., 2019. https://en.m.wikipedia.org/wiki/Octopus_cyanea 13 maret 2019.diakses 25 Mei 2019.

Riduwan., 2012. Dasar-Dasar Statistika.Alfabeta.Bandung $274 \mathrm{hlm}$.

Roper C. F. E,Sweeney M.J, dan Nauven C. E.,1984 species catalogue, Vol,3 Cephalopods of the world, An annotated and illustrated catalogue of species of interest to fisheries. FAO fish.Synop.(125) Vol. $3.277 \mathrm{p}$.

Syofian S., 2017.Statistika Terapan Untuk Perguruan Tinggi. Kencana Jakarta. $404 \mathrm{hlm}$

Wood, J. B., Kenchington, E. dan O'Dor, R.K. 1997. Reproduction and embryonic development time of Bathipolypus articus, a deep-sea octopod (Cephalopoda: Octpods). Malacologia Printed. 